\title{
Comparison of Transcatheter Mitral-Valve Repair and Surgical Mitral-Valve Repair in Elderly Patients with Mitral Regurgitation
}

\author{
Haoyong Yuan, MD, ${ }^{1,2}$ Tingting Wei, MD, ${ }^{3}$ Zhongshi Wu, MD, ${ }^{1,2}$ Ting Lu, MD, ${ }^{1,2}$ Jinlan Chen, MD, ${ }^{1}$ \\ Yifan Zeng, MD, ${ }^{1}$ Ling Tan, MD, ${ }^{1,2}$ Can Huang, $M D^{1,2}$ \\ ${ }^{1}$ Department of Cardiovascular Surgery, the Second Xiangya Hospital, Central South University, Changsha, Hunan, China \\ ${ }^{2}$ Engineering Laboratory of Hunan Province for Cardiovascular Biomaterials, Hunan, China \\ ${ }^{3}$ Department of Pediatrics, Hunan Provincial Maternal and Child Health Care Hospital, Hunan, China
}

\section{ABSTRACT}

Purpose: To summarize comparative studies of MitraClip versus surgical repair in typical, real-world elderly patients with severe mitral regurgitation (MR) and analyze the safety and effectiveness of these therapeutic options.

Methods: PubMed, Medline, Embase, and Cochrane Controlled Register of Trials (CENTRAL) were searched for comparative studies of transcatheter mitral-valve repair (TMVR) versus surgical mitral-valve repair (SMVR) in elderly patients with severe MR from January 2000 to June 2020. Statistical pooling for incidence estimates was performed according to a random-effects model with generic inverse-variance weighting, computing risk estimates with 95\% confidence intervals (CIs), using RevMan 5.3.

Results: A total of 14 reports comparing MitraClip with SMVR, enrolling 3355 patients with severe MR, were included in this study. Mean age, Logistic EuroSCORE, and incidence of diabetes mellitus (DM) were significantly higher in the MitraClip group, except the rate of patients with New York Heart Association (NYHA) class of >II and mean value of ejection fraction (EF). The arithmetic mean of freedom from acute mobility was similar. The 2 groups had equal allcause mortality at 30 days, but different at 1 year $(14 \%$ versus $9 \%$ ) and 3 years in 7 studies (37\% versus $25 \%$ ). The freedom from recurrent $M R \geq 3+$ was $88 \%$ and $97.3 \%$ at 30 days, $76.0 \%$ and $90.0 \%$ at 1 year, and $79 \%$ and $95 \%$ at 3 years in the MitraClip and surgical repair group, respectively.

Conclusion: Although MitraClip is safe and effective in selected high-risk patients, the surgery may be the only gold standard for "gray" patients. Further studies are needed to determine whether MitraClip should be recommended.

\section{INTRODUCTION}

Received October 27, 2020; received in revised form November 13, 2020; accepted December 1, 2020.

Correspondence: Can Huang, Department of Cardiovascular Surgery, Second Xiangya Hospital, Central South University, 139 Renmin Road, Changsha, Hunan 410011, P.R. Cbina; 86 73185292133; fax: 8673185292133 (e-mail: buangcan413@csu.edu.cn).
Mitral regurgitation (MR) due to left ventricular dilatation and ischemic or degenerative changes is the most common valvular lesion, occurring in $>6 \%$ of people older than 65 years [Niikura 2020]. Surgical mitral valve repair or replacement (SMVR), associated with high rates of MR relief (>95\%) and lower mortality $(1 \% \sim 3 \%)$, has been recommended as the gold standard of treatment for patients with symptomatic, severe MR [David 2013]. However, reasons such as old age ( $>80$ years), relevant comorbidities, and severely reduced $(<30 \%)$ left ventricular ejection fraction (LVEF) may result in approximately $50 \%$ of patients with severe MR not being referred for surgery [Goel 2014]. Thus, most patients with heart failure and severe MR are treated conservatively, and this high-risk group has few therapeutic alternatives [Stone 2018].

Since 2013, transcatheter mitral valve repair (TMVR) with the MitraClip device (Abbott, Abbott Park, IL) has been used. The multicenter registry, retrospective and prospective studies designed to compare transcatheter edge-to-edge mitral valve (MV) repair with optimal medical therapy proved that TMVR with the MitraClip is safe and results in durable MR reduction. Additionally, its use is associated with significant clinical and echocardiographic improvement. TMVR with MitraClip is thus an alternative for treating high-risk and inoperable patients with severe MR [De Rosa 2018]. Because of the excellent results of TMVR in terms of safety and effectiveness in elderly patients with high risk over the last decade, its use has been extended to elderly patients who do not actually have specific high-risk features, but rather fall into the low to intermediate risk category. Because of the strict inclusion/exclusion criteria and severe enrolling difficulties, however, only a few randomized controlled trials (the EVEREST II [Glower 2012] and HiRiDe trials), which were specifically designed to randomize elderly patients and retrospective unbalanced data, have been conducted on this topic.

Whether the access to the MitraClip should be opened to these "gray" patients and as the first-line option needs to be addressed, and there are several key issues that require further attention before this procedure becomes accepted on a large scale [Takagi 2017]. Our meta-analysis aimed to summarize comparative studies of the MitraClip versus surgical repair in typical, real-world elderly patients with severe MR and analyze the safety and effectiveness of these therapeutic options. 
METHODS

\section{Search Strategy and Registration}

This study was conducted according to the Preferred Reporting Items for Systematic Reviews and Meta-Analyses guidelines (PRISMA). This study was approved by the institutional review board of the Second Xiangya Hospital, Central South University.

Based on the PRISMA statement, PubMed, Medline, Embase, and Cochrane Controlled Register of Trials (CENTRAL) were searched for comparative studies of TMVR versus SMVR in the treatment of elderly patients with severe MR. The following search terms were used: "MitraClip," "transcatheter or percutaneous mitral valve repair," and "surgery mitral valve repair." Only English-language articles published in peer-reviewed journals from January 2000 to June 2020 were selected, and analyses were conducted by 2 independent reviewers.

\section{Eligibility Criteria}

Inclusion criteria for the meta-analysis were (1) observational or randomized original clinical studies comparing TMVR with SMVR for the treatment of elderly patients with severe MR, with the mean age of patients >60 years; (2) studies that reported data on patient baseline characteristics, inhospital outcomes, follow-up duration, mortality, and morbidity; (3) studies in which the mean follow-up time was $>6$ months; and (4) full-text articles. Exclusion criteria for the meta-analysis were (1) duplicate of the sample size and reports evaluated by 2 independent reviewers; (2) case reports/series; or (3) studies involving data from the national database. All the authors agreed on the final number of studies included.

\section{Data Extraction and Outcome Measurement}

Two authors (H.Y. and T.W.) systematically screened the titles and abstracts of publications retrieved using the search strategy to select studies that met the inclusion criteria outlined above. Any disagreement between them over the eligibility of particular studies was resolved through discussion and involvement of a third author (Z.W.), when necessary. First, baseline characteristics, including the name of the first author, year of publication, study design, number of patients, mean age of subjects, and mean time of follow-up, were gathered from each included article. In addition, the European Score, ejection fraction, grade of New York Heart Association (NYHA) classification and MR, history of previous cardiac surgery, and complications were collected for the evaluation of procedure risk. Acute complications, including stroke, acute kidney injury, and LOCOS, all-cause mortality, and recurrent MR grade $>3$, were used as the primary outcomes to evaluate the safety and efficiency of TMVR and SMVR.

\section{Data Analysis and Synthesis}

Continuous variables are reported as mean \pm standard deviation (SD), and categorical variables are expressed as $\mathrm{n}$ (\%). Statistical pooling for incidence estimates was performed according to a random-effects model with generic inversevariance weighting, computing risk estimates with $95 \%$ confidence intervals (CIs), using RevMan 5.3 (The Cochrane Collaboration, The NordicCochrane Centre, Copenhagen, Denmark). Hypothesis testing for superiority was set at the 2-tailed .05 level. Hypothesis testing for statistical homogeneity was set at the 2-tailed .10 level and based on the Cochran Q test, with I2 values of $25 \%, 50 \%$, and $75 \%$ representing mild, moderate, and severe heterogeneity, respectively.

\section{RESULTS}

\section{Search Results}

A total of 1742 articles were identified through the literature search, all written in the English language. After an initial screening, 14 reports [Niikura 2020; Alozie 2017; Kortlandt 2018; Feldman 2015; Paranskaya 2013; Anwer 2019; Swaans 2014; Taramasso 2012; De Bonis 2015; Buzzatti 2015; Gyoten 2020; Ondrus 2016; Buzzatti 2019; Ostovar 2018] comparing MitraClip with surgical MV repair, enrolling a total of 3355 patients with severe MR, were identified and included in qualitative and quantitative analyses. Only 1 study, the Endovascular Valve Edge-to-Edge Repair Study (EVEREST) II10, was a randomized controlled trial, whereas the others were observational comparative studies (Table 1) [Niikura 2020; Alozie 2017; Kortlandt 2018; Paranskaya 2013; Anwer 2019; Swaans 2014; Taramasso 2012; De Bonis 2015; Buzzatti 2015; Gyoten 2020; Ondrus 2016; Buzzatti 2019; Ostovar 2018]. The late follow-up duration was from 180 days [Ostovar 2018] to 5 years [Feldman 2015] (Tables 1 and 2).

\section{Patient Characteristics}

In all but 1 study [Ondrus 2016], the mean age in the MitraClip group was equal to or significantly higher than that in the surgical repair group, which was confirmed by the pooled analysis (pooled mean difference [MD] 5.27 years; $95 \%$ CI 2.20 to 8.34 years; $P<.0001$ ). Logistic EuroSCORE was employed to predict mortality and indicated significantly higher mortality in the MitraClip group (pooled MD 8.79; $95 \%$ CI 5.80 to $11.77 ; P<.0001$ ) (Figure 1 ). NYHA functional class and ejection fraction (EF) were used to evaluate left ventricular function. The pooled analysis demonstrated no significant differences in the rate of patients with NYHA class $>$ II (pooled odds ratio [OR] 2.04, 95\% CI 0.94 to 4.40 ) and the mean value of EF (pooled MD $-0.61 \%$; $95 \%$ CI $-3.74 \%$ to $2.51 \%$ ) between the 2 groups. A pooled analysis demonstrated that the rate of patients with diabetes mellitus (DM) (pooled OR 1.29, 95\% CI 1.05 to 1.59), chronic obstructive pulmonary disease (COPD) (pooled OR 1.81, 95\% CI 1.13 to 2.9), atrial fibrillation (AF) (pooled OR 2.11, 95\% CI 1.79 to 2.49), and previous cardiovascular surgery, including percutaneous coronary intervention (PCI) (pooled OR 2.44, 95\% CI 1.62 to 3.68 ) and coronary artery bypass graft (CABG) (pooled OR 4.77, 95\% CI 2.68 to 8.49), was much higher in the MitraClip group than in the surgical mitral valve repair group (Figure 1).

\section{Mortality at 30 Days, 1 Year, and $>3$ Years}

The 2 groups had equal all-cause mortality rates at 30 days, 
Table 1. Baseline Characteristics of the Patients

\begin{tabular}{|c|c|c|c|c|c|c|c|c|c|c|c|}
\hline Author & Study Design & TMVR & SMVR & TMVR & SMVR & TMVR & SMVR & TMVR & SMVR & TMVR & SMVR \\
\hline Alozie 2017 & $\begin{array}{c}\text { Retrospective } \\
\text { study }\end{array}$ & 42 & 42 & $\begin{array}{c}81.7 \pm \\
1.35\end{array}$ & $\begin{array}{c}81.7 \pm \\
1.35\end{array}$ & $\begin{array}{c}11.3 \pm \\
5.63\end{array}$ & $\begin{array}{c}12.1 \pm \\
10.6\end{array}$ & $30(67.9)$ & $27(64.3)$ & $11(21.4)$ & $11(21.4)$ \\
\hline Feldman 2015 & $\begin{array}{c}\text { Randomized } \\
\text { trial }\end{array}$ & 178 & 80 & $67 \pm 12.7$ & $\begin{array}{c}64.7 \pm \\
12.6\end{array}$ & & & $78(43.8)$ & $36(45.0)$ & $11(6.2)$ & $4(5.0)$ \\
\hline Paranskaya 2013 & $\begin{array}{c}\text { Retrospective } \\
\text { study }\end{array}$ & 24 & 26 & $80 \pm 5$ & $63 \pm 12$ & $12.3 \pm 3.7$ & $3.9 \pm 3.7$ & & & & \\
\hline Taramasso 2012 & $\begin{array}{l}\text { Retrospective } \\
\text { study }\end{array}$ & 91 & 52 & $68.4 \pm 9.2$ & $64.9 \pm 9.8$ & $21.9 \pm 4.8$ & $10.2 \pm 7.4$ & $47(51.6)$ & $35(63.3)$ & 14 (15.4) & $9(17.3)$ \\
\hline De Bonis 2015 & $\begin{array}{l}\text { Retrospective } \\
\text { study }\end{array}$ & 55 & 65 & $\begin{array}{c}68.3 \pm \\
9.17\end{array}$ & $\begin{array}{l}63.2 \pm \\
10.05\end{array}$ & $\begin{array}{c}18.8(10.8 \\
\text { to } 28.2)\end{array}$ & $\begin{array}{c}11 \text { (9 to } \\
13)\end{array}$ & $35(63.6)$ & $40(61.5)$ & $10(18.2)$ & $16(24.6)$ \\
\hline Buzzatti 2015 & $\begin{array}{c}\text { Retrospective } \\
\text { study }\end{array}$ & 25 & 35 & $84.5 \pm 3.2$ & $81.9 \pm 2.0$ & $\begin{array}{l}19.4(11.1 \\
\text { to } 29.0)\end{array}$ & $\begin{array}{c}8.4 \text { (7.0 to } \\
10.1)\end{array}$ & $17(68.0)$ & $13(37)$ & & \\
\hline Gyoten 2020 & $\begin{array}{c}\text { Retrospective } \\
\text { study }\end{array}$ & 85 & 47 & $72 \pm 8.5$ & $68 \pm 9.6$ & $33.5 \pm 20$ & $25.0 \pm 22$ & $62(73.0)$ & $35(74.0)$ & $22(26.0)$ & $11(23.0)$ \\
\hline Ondrus 2016 & $\begin{array}{l}\text { Retrospective } \\
\text { study }\end{array}$ & 24 & 48 & $75 \pm 9$ & $76 \pm 4$ & $18 \pm 14$ & $14 \pm 11$ & & & & \\
\hline
\end{tabular}

Data are $n$, mean $\pm S D$, median (range), or $n(\%)$.

and a pooled analysis indicated no statistically significant difference in early mortality (30 days) between the MitraClip and the surgical repair groups (pooled OR 0.88, 95\% CI 0.53 to 1.47$)$. Of the 11 studies that published 1 -year all-cause mortality rates, the TMVR and SMVR groups showed different mean mortalities (14\% versus $9 \%$, respectively), which is similar to the 3 -year all-cause mortality rates in 7 studies, with mean mortalities of $37 \%$ versus $25 \%$, respectively. Pooled analysis indicated a statistically significant difference in the 1-year (pooled OR 1.79, 95\% CI 1.4 to 2.28 ) and $>3$-year (pooled OR 2.26, 95\% CI 1.04 to 4.92) all-cause mortality between the MitraClip and surgical repair groups (Figure 2).

\section{Acute Mobility and Recurrent MR Grade >2 at 30 Days, 1} Year, and 3 Years

The arithmetic mean of freedom rates from acute mobility including stroke, acute kidney injury, and LOCOS was similar in the MitraClip and surgical repair groups. These rates from recurrent $M R \geq 3$ + were $88 \%$ and $97.3 \%$ at 30 days, $76.0 \%$ and $90.0 \%$ at 1 year, and $79 \%$ and $95 \%$ at 3 years in the MitraClip and surgical repair group, respectively. Pooled analysis indicated a significantly higher incidence of recurrent $M R$ in the MitraClip group than in the surgical repair group at 30 days (pooled OR 9.51; 95\% CI 5.38 to $16.83 ; P$ $<.00001$ ), 1 year (pooled OR 3.14; $95 \%$ CI 1.20 to $8.25 ; P<$ .00001 ), and 3 years (pooled OR 8.47; $95 \%$ CI 4.76 to 15.10 ; $P<.00001)$ (Figure 3).

\section{DISCUSSION}

Since the percutaneous mitral valve repair with the MitraClip device was first used in Europe in 2013, it has always been compared to medical therapy, including beta-blockers 
Table 2. Baseline Characteristics of the Patients

\begin{tabular}{|c|c|c|c|c|c|c|c|c|c|c|c|c|c|c|}
\hline Author & TMVR & SMVR & TMVR & SMVR & TMVR & SMVR & TMVR & SMVR & TMVR & SMVR & TMVR & SMVR & TMVR & SMVR \\
\hline $\begin{array}{l}\text { Alozie } \\
2017\end{array}$ & $\begin{array}{c}18 \\
(42.9)\end{array}$ & $\begin{array}{c}14 \\
(33.3)\end{array}$ & $\begin{array}{c}29 \\
(69.0)\end{array}$ & $\begin{array}{c}23 \\
(54.8)\end{array}$ & $\begin{array}{c}14 \\
(33.3)\end{array}$ & $\begin{array}{c}10 \\
(23.8)\end{array}$ & $\begin{array}{c}26 \\
(61.9)\end{array}$ & $\begin{array}{c}31 \\
(73.8)\end{array}$ & $\begin{array}{c}32 \\
(76.2)\end{array}$ & $\begin{array}{c}26 \\
(61.9)\end{array}$ & $7(16.7)$ & & & $\begin{array}{c}16 \\
(38.0)\end{array}$ \\
\hline $\begin{array}{l}\text { Feldman } \\
2015\end{array}$ & $14(7.9)$ & $1(8.8)$ & $\begin{array}{c}56 \\
(32.9)\end{array}$ & $\begin{array}{c}29 \\
(38.7)\end{array}$ & $\begin{array}{c}27 \\
(15.3)\end{array}$ & $\begin{array}{c}11 \\
(13.8)\end{array}$ & $\begin{array}{c}83 \\
(46.9)\end{array}$ & $\begin{array}{c}35 \\
(43.8)\end{array}$ & & & $\begin{array}{c}42 \\
(23.7)\end{array}$ & $\begin{array}{c}13 \\
(16.3)\end{array}$ & $\begin{array}{c}37 \\
(20.8)\end{array}$ & $\begin{array}{c}13 \\
(16.3)\end{array}$ \\
\hline $\begin{array}{l}\text { Paranskaya } \\
2013\end{array}$ & $12(15)$ & $2(7.7)$ & $\begin{array}{c}15 \\
(62.5)\end{array}$ & $\begin{array}{c}14 \\
(53.8)\end{array}$ & $\begin{array}{c}5 \\
(20.8)\end{array}$ & $2(7.7)$ & $\begin{array}{c}14 \\
(58.3)\end{array}$ & $\begin{array}{c}6 \\
(23.1)\end{array}$ & & & & & & \\
\hline $\begin{array}{l}\text { Taramasso } \\
2012\end{array}$ & $\begin{array}{c}14 \\
(26.9)\end{array}$ & $9(9.9)$ & $\begin{array}{c}37 \\
(17.3)\end{array}$ & $\begin{array}{c}29 \\
(32.0)\end{array}$ & $\begin{array}{c}11 \\
(21.2)\end{array}$ & $3(3.3)$ & $\begin{array}{c}44 \\
(48.3)\end{array}$ & $\begin{array}{c}37 \\
(71.2)\end{array}$ & $\begin{array}{c}30 \\
(57.7)\end{array}$ & $\begin{array}{c}16 \\
(17.6)\end{array}$ & $\begin{array}{c}12 \\
(23.1)\end{array}$ & $9(9.9)$ & & \\
\hline $\begin{array}{l}\text { De Bonis } \\
2015\end{array}$ & & & $\begin{array}{c}19 \\
(34.5)\end{array}$ & $\begin{array}{c}14 \\
(21.5)\end{array}$ & & & & & & & & & & \\
\hline $\begin{array}{l}\text { Buzzatti } \\
2015\end{array}$ & & & $\begin{array}{c}10 \\
(40.0)\end{array}$ & $\begin{array}{c}7 \\
(20.0)\end{array}$ & $\begin{array}{c}6 \\
(24.0)\end{array}$ & $3(9.0)$ & $\begin{array}{c}7 \\
(28.0)\end{array}$ & $\begin{array}{c}7 \\
(20.0)\end{array}$ & $\begin{array}{c}19 \\
(76.0)\end{array}$ & $\begin{array}{c}20 \\
(57.0)\end{array}$ & & & $3(12.0)$ & $2(6.0)$ \\
\hline $\begin{array}{l}\text { Gyoten } \\
2020\end{array}$ & $\begin{array}{c}37 \\
(44.0)\end{array}$ & $\begin{array}{c}14 \\
(30.0)\end{array}$ & $\begin{array}{c}51 \\
(60.0)\end{array}$ & $\begin{array}{c}26 \\
(55.0)\end{array}$ & $\begin{array}{c}15 \\
(18.0)\end{array}$ & $7(15.0)$ & & & $\begin{array}{c}36 \\
(42.0)\end{array}$ & $\begin{array}{c}12 \\
(26.0)\end{array}$ & $\begin{array}{c}36 \\
(42.0)\end{array}$ & $9(19.0)$ & & \\
\hline $\begin{array}{l}\text { Ondrus } \\
2016\end{array}$ & & & $\begin{array}{c}18 \\
(75.0)\end{array}$ & $\begin{array}{c}33 \\
(69.0)\end{array}$ & & & $\begin{array}{c}15 \\
(63.0)\end{array}$ & & & & & & & \\
\hline
\end{tabular}

Data are $n(\%)$.

CAD indicates coronary artery disease; CRF, chronic renal failure.

and angiotensin-converting enzyme (ACE) inhibitors or angiotensin II receptor blockers and has been confirmed to be safe and efficient, especially for the high-risk patient with functional MR [Mendirichaga 2017]. Recently, new techniques have been developed, and the use of the MitraClip has increased liberally to treat the intermediate-risk patient with either functional or degenerative MR who still qualifies for surgery. In this meta-analysis, we compared percutaneous mitral valve repair with MitraClip and surgical mitral valve repair in elderly patients to present the available evidence regarding the use of MitraClip.

Because of the strict enrollment standards, little data could be extracted from the randomized controlled trial studies. In this analysis, only 1 publication [Feldman 2015] was of this nature, spanning the period 2011 (1-year follow up) to 2015 ( $>5$-year follow up). Although the potential biases are greater for nonrandomized studies, patients enrolled in retrospective studies might be representative of patients typically seen in real-world clinical practice. Patient numbers in 4 publications included in our analysis were $>100$ each, which may also increase the heterogeneity [Niikura 2020; Kortlandt 2018; Feldman 2015; Buzzatti 2019]. We must view our analysis in the context of its limitations, and results should be always interpreted with caution when nonrandomized studies are included in meta-analysis.

It is important to note the distinct clinical characteristics of the transcatheter patients, who were considerably older and more commonly affected with significant comorbidities such as DM, COPD, and AF in comparison with those who had surgical repair. EuroSCORE, NYHA functional class, $\mathrm{EF}$, and previous cardiac surgery, including PCI and CABG, were used to evaluate risk, as well as left ventricular function. 


\section{Mean age of the patients}

\begin{tabular}{|c|c|c|c|c|c|c|c|c|c|c|c|c|}
\hline \multirow[b]{2}{*}{ Study or Subgroup } & \multicolumn{2}{|c|}{ TMVR } & \multicolumn{3}{|r|}{ SMVR } & \multirow[b]{2}{*}{ Total } & \multirow[b]{2}{*}{ Weight } & \multirow{2}{*}{$\begin{array}{l}\text { Mean Difference } \\
\text { IV. Random. } 95 \% \mathrm{Cl}\end{array}$} & \multirow{2}{*}{\multicolumn{3}{|c|}{$\begin{array}{l}\text { Mean Difference } \\
\text { IV. Random, } 95 \% \mathrm{Cl}\end{array}$}} & \multirow{5}{*}{$\mathrm{Cl}$} \\
\hline & Mean & $S D$ & Total & Mean & SD & & & & & & & \\
\hline Anthony Alozie 2017 & 81.7 & 1.35 & 42 & 81.7 & 1.35 & 42 & $7.6 \%$ & $0.00[-0.58,0.58]$ & & & & \\
\hline Friso Kortlandt 2018 & 73.96 & 10.45 & 586 & 73.96 & 9.84 & 173 & $7.5 \%$ & $0.00[-1.69,1.69]$ & & & 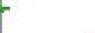 & \\
\hline Hiroki Nilkura,2020 & 82 & 7.8 & 249 & 64.3 & 12.4 & 628 & $7.5 \%$ & $17.70[16.33,19.07]$ & & & & \\
\hline Laura Mauri 2015 & 67 & 12.7 & 178 & 64.7 & 12.6 & 80 & $7.0 \%$ & $2.30[-1.03,5,63]$ & & & & \\
\hline Lenard Conradi 2012 & 72.4 & 8.1 & 95 & 645 & 11.4 & 76 & $7.1 \%$ & $7.90[4.86,10.94]$ & & & & \\
\hline Liliya Paranskaya 2012 & 80 & 5 & 24 & 63 & 12 & 26 & $6.3 \%$ & $17.00[11.97,22.03]$ & & & & \\
\hline Lucman A. Anwer2019 & 75.7 & 8.6 & 56 & 68.6 & 13.1 & 75 & $6.9 \%$ & $7.10[3.38,10.82]$ & & & & \\
\hline Martin J. Swaans 2014 & 74.9 & 9.4 & 139 & 70.2 & 9.5 & 53 & $7.1 \%$ & $4.70[1.70,7.70]$ & & & & \\
\hline Maurizio Taramasso 2012 & 68.4 & 9.2 & 52 & 64.9 & 9.8 & 91 & $7.0 \%$ & $3.50[0.29,6.71]$ & & & 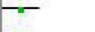 & \\
\hline Michele De Bonis 2016 & 68.3 & 9.17 & 55 & 63.2 & 10.05 & 65 & $7.0 \%$ & $5.10[1.66,8.54]$ & & & $\longrightarrow$ & \\
\hline Nicola Buzzatti 2015 & 84.5 & 3.2 & 25 & 81.9 & 2 & 35 & $7.5 \%$ & $2.60[1.18,4.02]$ & & & - & \\
\hline Nicola Buzzatti 2019 & 82.9 & 3.5 & 100 & 78.8 & 3.13 & 206 & $7.6 \%$ & $4.10[3.29,4.91]$ & & & $=$ & \\
\hline Takayuki Gyoten 2020 & 72 & 8.5 & 47 & 68 & 9 & 85 & $7.1 \%$ & $4.00[0.91,7.09]$ & & & - & \\
\hline Tomas Ondrus 2016 & 75 & 9 & 24 & 76 & 4 & 48 & $6.8 \%$ & $=1.00[-4.77,2.77]$ & & & & \\
\hline Total $(95 \% \mathrm{Cl})$ & & & 1672 & & & 1683 & $100.0 \%$ & $5.27[2.20,8.34]$ & & & & \\
\hline $\begin{array}{l}\text { Heterogeneity: } \operatorname{Tau}^{2}=32.19 \\
\text { Test for overall effact: } Z=3\end{array}$ & $\begin{array}{l}\mathrm{Chi}^{2}= \\
66(\mathrm{P}=\end{array}$ & $\begin{array}{l}616.64 \\
0.0008)\end{array}$ & $\mathrm{df}=13$ & $(P<0$. & .00001 & $1^{2}=98$ & & & -20 & $\begin{array}{c}-10 \quad 0 \\
\text { TMVR }\end{array}$ & $\begin{array}{r}10 \\
\text { SMVR }\end{array}$ & 20 \\
\hline
\end{tabular}

\section{Euroscore of the patients}

\begin{tabular}{|c|c|c|c|c|c|c|c|c|c|c|c|c|c|}
\hline \multirow[b]{2}{*}{ Study or Subaroup } & \multicolumn{3}{|c|}{ European Scora for the TMVR } & \multicolumn{4}{|c|}{ European Score for the SMVR } & \multicolumn{2}{|l|}{ Mean Difference } & \multirow{2}{*}{\multicolumn{4}{|c|}{$\begin{array}{l}\text { Mean Difference } \\
\text { M. Randiom. } 95 \% \text { CI }\end{array}$}} \\
\hline & Moan & sp & Total & Mosan & SD & Total & Weight & IV. Random, $95 \% \mathrm{Cl}$ & Yoar & & & & \\
\hline Lenard Conradi 2012 & 39.7 & 18.7 & 05 & 10.1 & 8.7 & 76 & $9.5 \%$ & $23.60[19.36,27.84]$ & 2012 & & & 7 & \\
\hline Maurizo Taramasso 2012 & 21.9 & 4.8 & 91 & 10.2 & 7.4 & 52 & $11.0 \%$ & $11.70[9.46,13.94]$ & 2012 & & & $=$ & \\
\hline Martin J. Swanans 2014 & 23.9 & 16 & 139 & 14.2 & a. 9 & 53 & $10,0 \%$ & $9.70[8.12,13.26]$ & 2014 & & & $\pi$ & \\
\hline Nicola Buzzatti 2015 & 19.725 & 4.475 & 25 & 8.48 & 0.935 & 35 & $112 \%$ & $11.25[9.46,13.03]$ & 2015 & & & $=$ & \\
\hline Tomas Ondrus 2016 & 18 & 14 & 24 & 14 & 11 & 48 & $7.6 \%$ & $4.00[-2.41,10.41]$ & 2016 & & & & \\
\hline Michele De Bonis 2016 & 18.8 & 4.35 & 55 & 11 & 1.15 & 65 & $11.5 \%$ & $7.80[6.62,8.96]$ & 2016 & & & . & \\
\hline Anthony Alozie 2017 & 11.3 & 5.63 & 42 & 12.1 & 10.6 & 42 & $10.0 \%$ & $-0.80[-4,43,2.83]$ & 2017 & & & & \\
\hline Friso Kortiandt 2018 & 8.09 & 7.23 & 568 & 4.36 & 3.BA & 173 & $11.6 \%$ & $3.67\{2.84,4.50\}$ & 2018 & & & " & \\
\hline Liliya Paranskaya 2012 & 12.3 & 3.7 & 24 & 3.9 & 3.7 & 26 & $11.1 \%$ & $8.40[6.35,10.45]$ & 2020 & & & $=$ & \\
\hline Takayuki Gyoten 2020 & 33.5 & 20 & 85 & 25 & 22 & 47 & $6.7 \%$ & $8.50[0.91,16.09]$ & 2020 & & & & \\
\hline Total $(95 \% \mathrm{Cl})$ & & & 1148 & & & 617 & $100.0 \%$ & $8.79[5.80,11.77]$ & & & & $\bullet$ & \\
\hline $\begin{array}{l}\text { Heterogeneity: } \text { Tau }^{2}=19.8 \\
\text { Test for overall affect } Z=5\end{array}$ & $\begin{array}{l}C \mathrm{Ch}^{2}=1 \mathrm{~A} 2.8 \\
7 \mathrm{P}^{\mathrm{P}}<0.000\end{array}$ & $=9(\mathrm{P}$ & $0001 \%: 1$ & $95 \%$ & & & & & & -50 & -25 & ${ }_{\text {SMNR }} 25$ & 50 \\
\hline
\end{tabular}

\section{3. previous $\mathrm{PCl}$ before therapy}

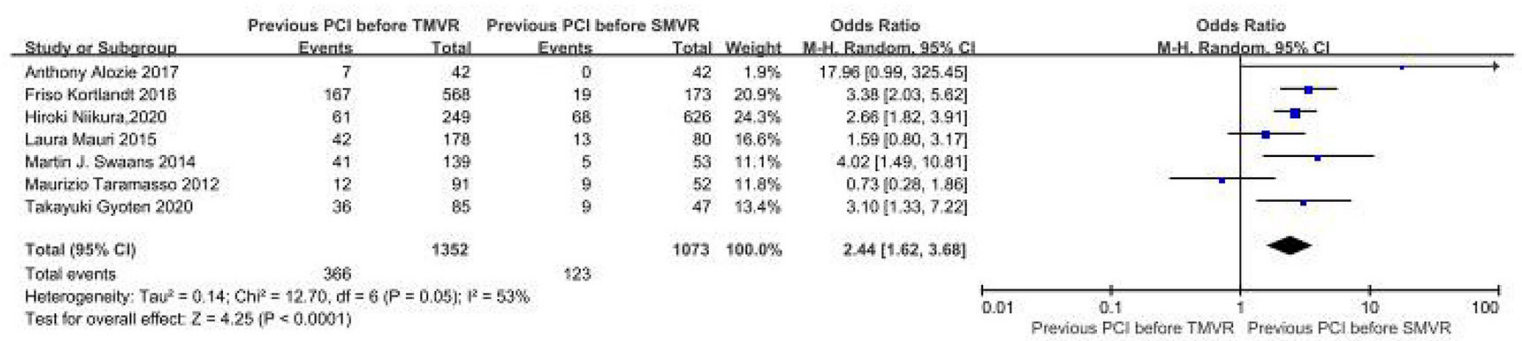

\section{4. previous $C A B G$ before therapy}

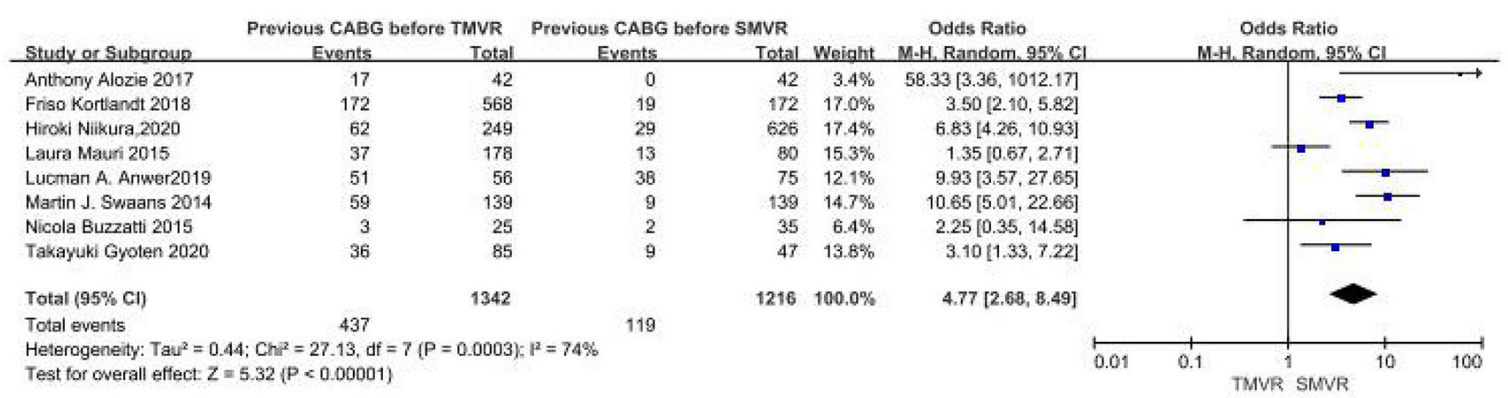

Figure 1. Baseline characteristics of elderly patients with severe MR. 


\section{1. mortality at 30-day}

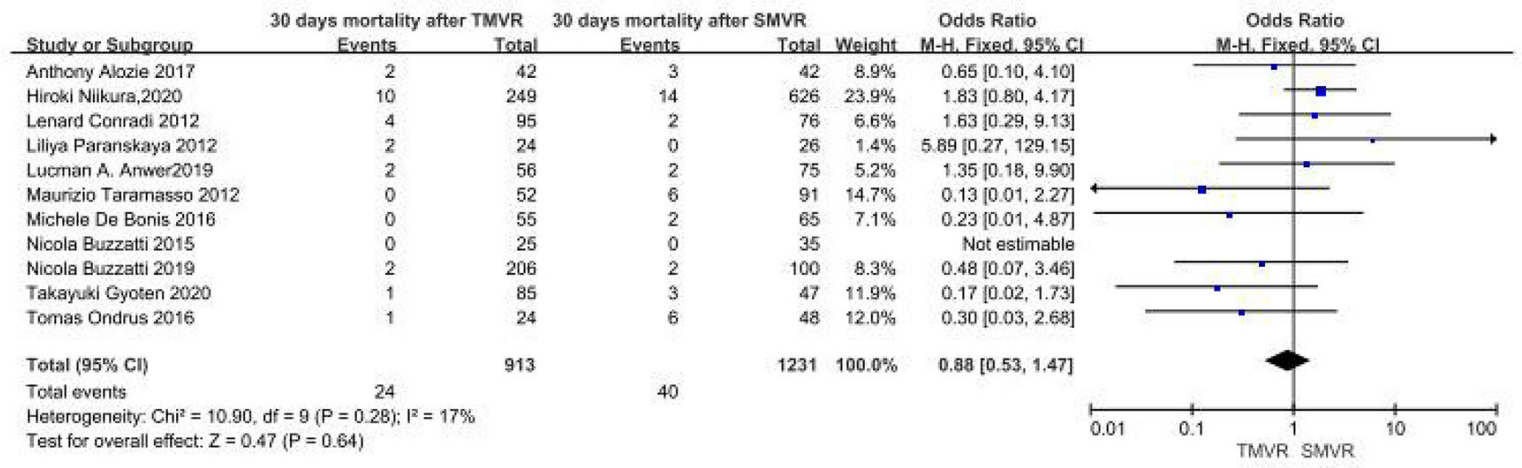

\section{2. mortality at 1 year}

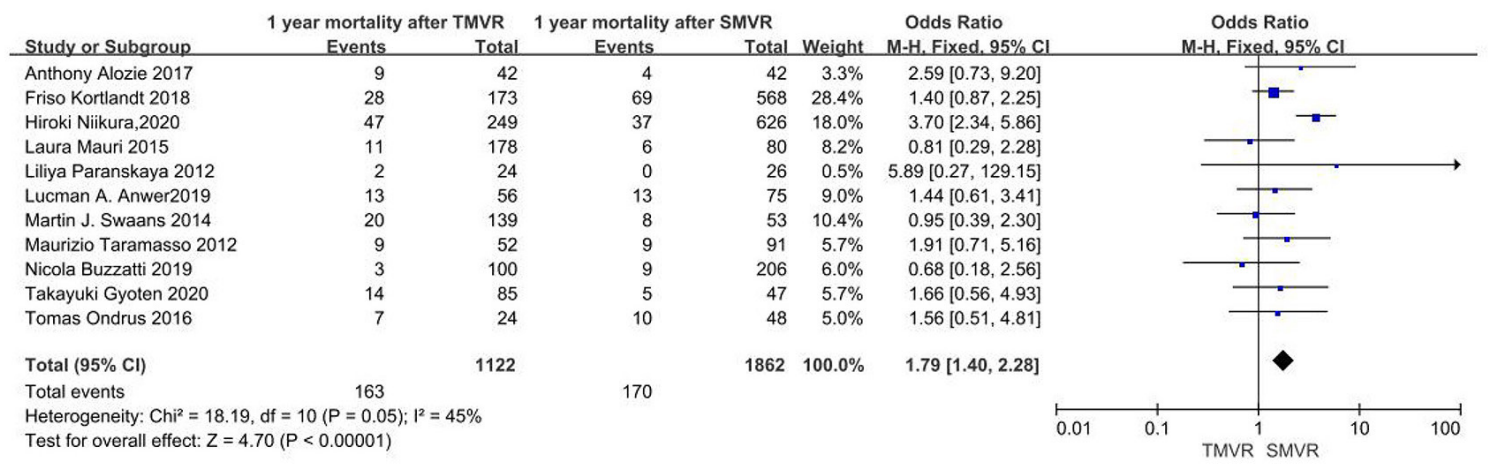

\section{3. mortality over 3 year}

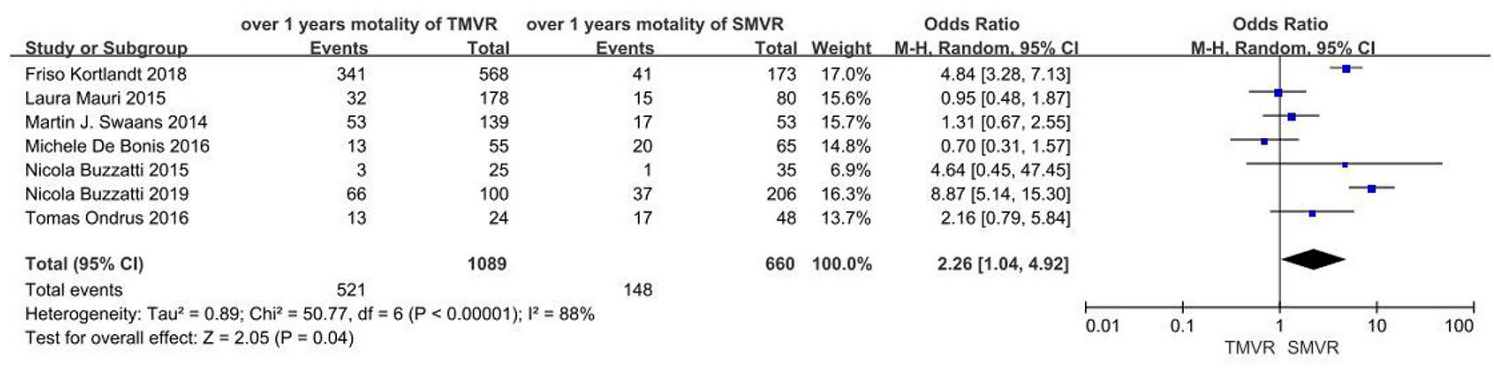

Figure 2. Mortality at 30 days, 1 year, and 3 years.

Except for the EuroSCORE and previous cardiac surgery, the other factors showed no significant difference between groups.

The present findings should be interpreted with caution because of higher-risk profiles (considerably old, significant comorbidities, lower EuroSCORE, and previous cardiac surgery) in the MitraClip group versus the surgical repair group. Similar survival rates despite higher-risk profiles suggest that at least, the MitraClip procedure may not achieve a worse survival rate than surgical repair at 30 days. However, different mean all-cause mortalities (14\% versus 9\%, respectively) in 1 - and 3 -year mortality (37\% versus $25 \%$, respectively) were found in our meta-analysis. Potential predictors of cardiac mortality, including age, EuroSCORE, NYHA functional class, EF, and previous cardiac surgery, were evaluated by Cox proportional hazard regression in 4 separate studies and demonstrated that there was no significant difference between the 2 groups [Niikura 2020; Anwer 2019; De Bonis 2015; Ostovar 2018].

As predicted, the MitraClip was confirmed to be safer than surgery in the short term. Indeed, the arithmetic mean of freedom rates from acute postoperative complications including stroke, acute kidney injury, and LOCOS were similar in the MitraClip and surgical repair groups. These results highlight the point that in end-stage patients who are not suitable for surgery, a less-invasive approach such as MitraClip therapy should be considered to improve clinical outcomes. Despite good results having been reported in the presence of an adverse valve morphology [Franzen 2010], the anatomic eligibility of patients remains an open issue. In contrast, in-hospital mortality in the surgical group was acceptable, confirming that appropriate patient selection is the key to 


\section{1.the recurrent $3+M R$ at 30-day}

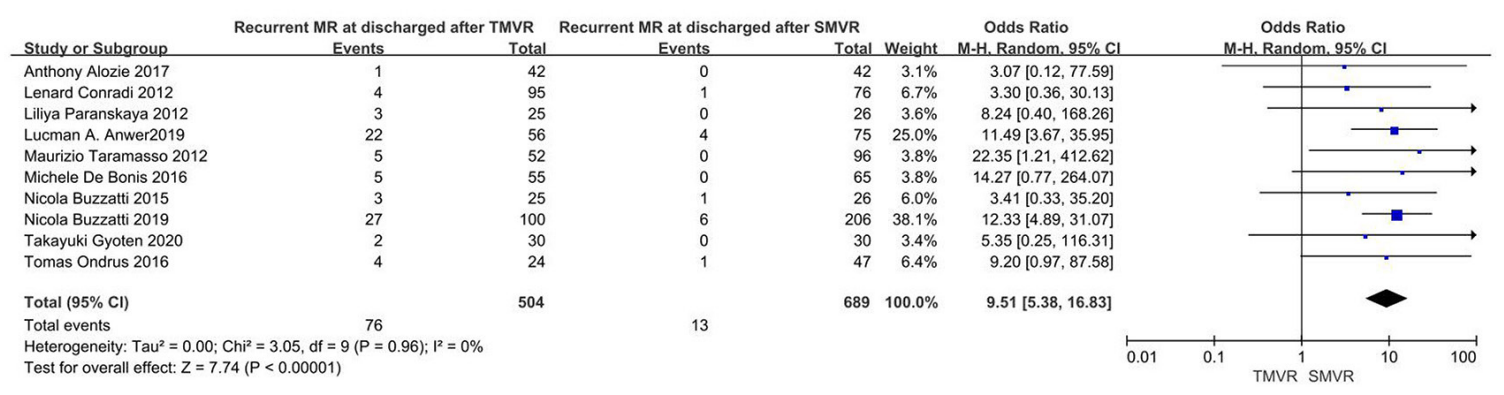

\section{2.the recurrent 3+MR at 1-year}

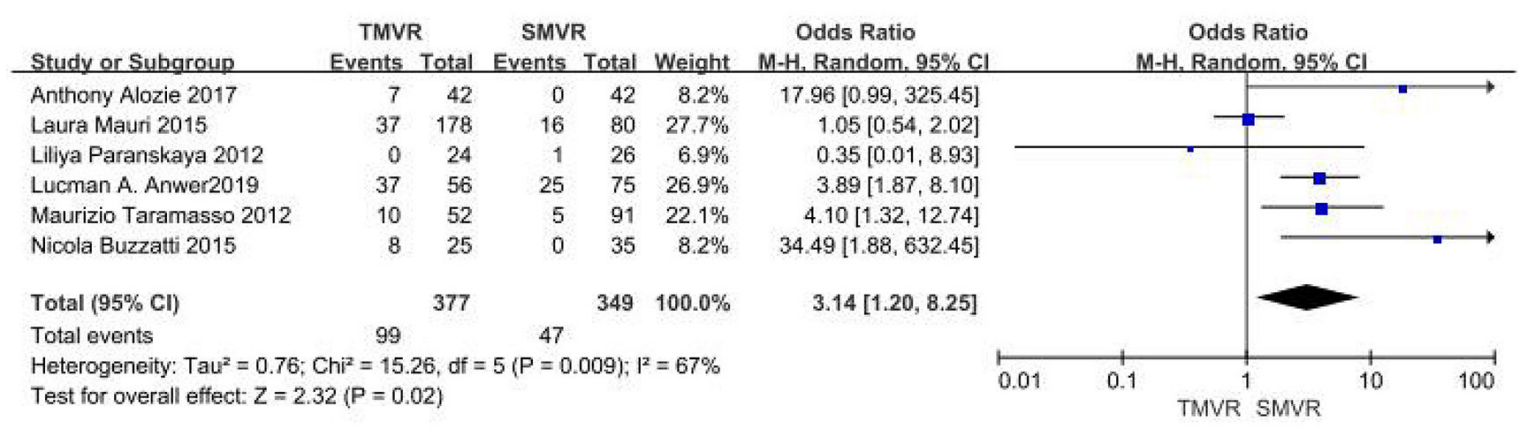

\section{3. the recurrent 3+MR at over 3-years}

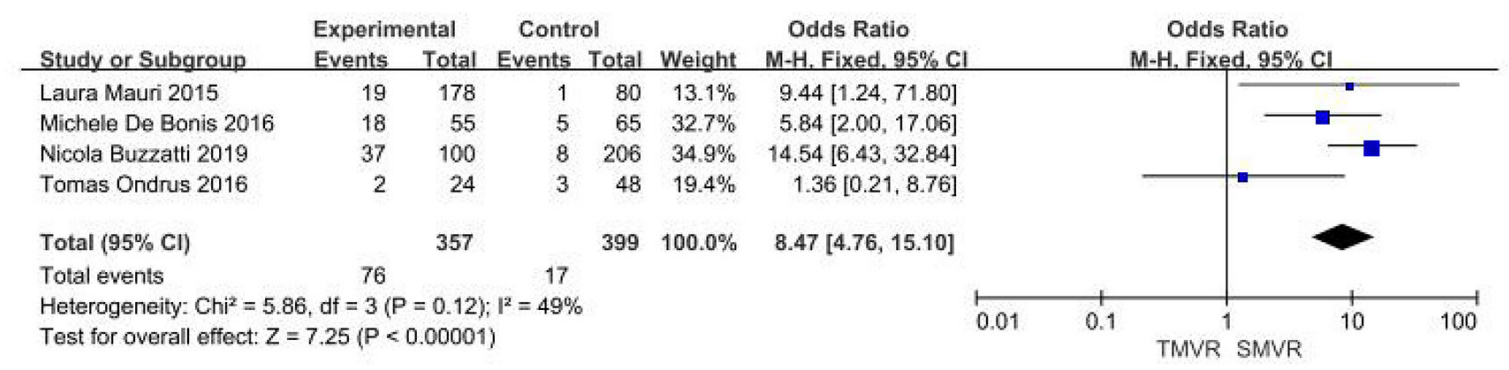

Figure 3. Recurrent $M R \geq 3+$ at 30 days, 1 year, and $>3$ years.

achieving good results.

Residual MR after surgical repair is associated with poor survival. Multivariate analysis in 1 study identified failure of acute procedural success, defined as persisting MR grade 3+ or 4+, as a significant independent predictor of medium-term follow-up all-cause mortality. In our analysis, the arithmetic mean of freedom rates from recurrent $M R \geq 3+$ were $88 \%$ and $97.3 \%$ at 30 days, $76.0 \%$ and $90.0 \%$ at 1 year, and $79 \%$ and $95 \%$ at 3 years in the MitraClip and surgical repair groups, respectively. A pooled analysis indicated a significantly higher incidence of recurrent MR in the MitraClip than in the surgical repair group at 30 days. However, the primary finding of the EVEREST II 5-year follow-up is the durability of MR reduction with Mitraclip. Although more severe residual MR was seen in the MitraClip group than in the surgical repair group, long-term survival and left ventricular function after percutaneous repair were similar. Because the majority of patients had degenerative MR in the EVEREST II trial and rate of postoperative MR was lower in the surgical patients, the negative prognostic impact of persisting $M R$ could not be demonstrated in the surgical group. In multiple studies including functional and degenerative MR patients, it was revealed that the residual degree of MR immediately after MitraClip placement was a predictor for the composite endpoint of mortality. Hence, we believe that MitraClip therapy in selected high-risk patients with functional $M R$ is a safe procedure. Larger numbers of patients with degenerative MR and a longer follow-up would be necessary to establish efficacy of the percutaneous approach compared with surgery repair.

In conclusion, this study shows that MitraClip therapy is safe and efficient in selected high-risk patients. Because of 
the long-term survival rate and high rate of freedom from the recurrence of MR grade $>3$, the surgery may be the gold standard for "gray" patients. Considering the variable characteristics of patients included in the comparison between the 2 groups and the few randomized controlled trial studies, further studies are needed to determine whether use of the MitraClip should increase.

\section{ACKNOWLEDGMENTS}

Dr Zhongshi Wu was supported by the National Natural Science Foundation of China (81771991) and National Key Research and Development Project (2016YFC1101002).

\section{REFERENCES}

Alozie A, Paranskaya L, Westphal B, et al. Clinical outcomes of conventional surgery versus MitraClip ${ }^{\circledR}$ therapy for moderate to severe symptomatic mitral valve regurgitation in the elderly population: An institutional experience. BMC Cardiovasc Disor 2017;17:85.

Anwer LA, Dearani JA, Daly RC, et al. Degenerative mitral regurgitation after nonmitral cardiac surgery: Mitraclip versus surgical reconstruction. Ann Thorac Surg 2019;107:725-731.

Buzzatti N, Maisano F, Latib A, et al. Comparison of outcomes of percutaneous MitraClip versus surgical repair or replacement for degenerative mitral regurgitation in octogenarians. Am J Cardiol 2015;115:487-492.

Buzzatti N, Van Hemelrijck M, Denti P, et al. Transcatheter or surgical repair for degenerative mitral regurgitation in elderly patients: A propensity-weighted analysis. J Thorac Cardiovasc Surg 2019;158:86-94.

David TE, Armstrong S, McCrindle BW, Manlhiot C. Late outcomes of mitral valve repair for mitral regurgitation due to degenerative disease. Circulation 2013;127:1485-1492.

De Bonis M, Taramasso M, Lapenna E, et al. MitraClip therapy and surgical edge-to-edge repair in patients with severe left ventricular dysfunction and secondary mitral regurgitation: Mid-term results of a singlecentre experience. Eur J Cardio-Thorac 2015;49:255-262.

De Rosa R, Silverio A, Baldi C, et al. Transcatheter repair of functional mitral regurgitation in heart failure patients-A meta-analysis of 23 studies on MitraClip implantation. Circ J 2018;82:2800-2810.

Feldman T, Kar S, Elmariah S, et al. Randomized comparison of percutaneous repair and surgery for mitral regurgitation: 5-Year results of EVEREST II. J Am Coll Cardiol 2015;66:2844-2854.

Franzen O, Baldus S, Rudolph V, et al. Acute outcomes of MitraClip therapy for mitral regurgitation in high-surgical-risk patients: Emphasis on adverse valve morphology and severe left ventricular dysfunction. Eur Heart J 2010;31:1373-1381.

Glower D, Ailawadi G, Argenziano M, et al. EVEREST II randomized clinical trial: Predictors of mitral valve replacement in de novo surgery or after the MitraClip procedure. J Thorac Cardiovasc Surg 2012;143(4 suppl):S60-S63.

Goel SS, Bajaj N, Aggarwal B, et al. Prevalence and outcomes of unoperated patients with severe symptomatic mitral regurgitation and heart failure: Comprehensive analysis to determine the potential role of MitraClip for this unmet need. J Am Coll Cardiol 2014;63:185-186.

Gyoten T, Schenk S, Rochor K, et al. Outcome comparison of mitral valve surgery and MitraClip therapy in patients with severely reduced left ventricular dysfunction. ESC Heart Fail 2020;7:1781-1790.

Kortlandt F, Velu J, Schurer R, et al. Survival after MitraClip treatment compared to surgical and conservative treatment for high-surgical-risk patients with mitral regurgitation. Circ Cardiovasc Interv 2018;11:e5985.

Mendirichaga R, Singh V, Blumer V, et al. Transcatheter mitral valve repair with MitraClip for symptomatic functional mitral valve regurgitation. Am J Cardiol 2017;120:708-715.

Niikura H, Gossl M, Bae R, et al. Impact of the commercial introduction of transcatheter mitral valve repair on mitral surgical practice. J Am Heart Assoc 2020;9:e14874.

Ondrus T, Bartunek J, Vanderheyden M, et al. Minimally invasive mitral valve repair for functional mitral regurgitation in severe heart failure: MitraClip versus minimally invasive surgical approach. Interact Cardiov Th 2016;23:784-789.

Ostovar R, Claus T, Hartrumpf M, et al. MitraClip for high-risk patients with significant mitral insufficiency: Shall we unreservedly recommend it? Thorac Cardiovasc Surg 2018;66:537-544.

Paranskaya L, D’Ancona G, Bozdag-Turan I, et al. Percutaneous versus surgical repair of mitral valve regurgitation: Single institution early and midterm outcomes. Can J Cardiol 2013;29:452-459.

Stone GW, Lindenfeld J, Abraham WT, et al. Transcatheter mitral-valve repair in patients with heart failure. N Engl J Med 2018;379:2307-2318.

Swaans MJ, Bakker AL, Alipour A, et al. Survival of transcatheter mitral valve repair compared with surgical and conservative treatment in highsurgical-risk patients. JACC Cardiovasc Interv 2014;7:875-881.

Takagi H, Ando T, Umemoto T. A review of comparative studies of MitraClip versus surgical repair for mitral regurgitation. Int J Cardiol 2017;228:289-294.

Taramasso M, Denti P, Buzzatti N, et al. Mitraclip therapy and surgical mitral repair in patients with moderate to severe left ventricular failure causing functional mitral regurgitation: A single-centre experience. Eur J Cardio-Thorac 2012;42:920-926. 